\title{
The Mutagenic Potential Caused by the Emissions from Combustion of Crude Glycerin and Diesel Fuel
}

\author{
Daniel Terruggi Mazak ${ }^{1}$, Ivonete Ávila ${ }^{1,2^{*}}$, Paula Manoel Crnkovic ${ }^{1}$, Aymer Yeferson \\ Maturana Cordoba and Josmar Davilson Pagliuso ${ }^{1}$ \\ ${ }^{I}$ Departamento de Engenharia Mecânica; Escola de Engenharia de São Carlos; Universidade de São Paulo; São \\ Carlos - SP - Brasil. ${ }^{2}$ Departamento de Energia; Faculdade de Engenharia de Guaratinguetá; Universidade \\ Estadual Paulista; Guaratinguetá - SP - Brasil
}

\begin{abstract}
This study evaluated the use of crude glycerin as an alternative of energy generation to replace the traditional fuels. The Tradescantia stamen hair mutation assay (Trad-SH) was applied to study the mutagenic effects caused by the emissions generated in the direct combustion of diesel oil and glycerin in a flame tube furnace. Tradescantia inflorescences were exposed to gaseous emissions from the combustion tests in a fumigation chamber for 30-40 min. The analysis of variance and the Tukey test were applied to compare the differences between six test groups (intoxicated with emissions from glycerin and diesel oil combustion) and a control group. Only one glycerin group showed statistical differences (0.05), possibly due to the complexity of the burning process and impurities, besides the acrolein present in its emissions. The high heating value (HHV) of crude glycerin (25.5 MJ/kg) was lower than diesel oil (45.19 MJ/kg), but it was comparable to other fuels. Although the use of glycerin as a biofuel could be an important aspect to be considered, the results showed that the glycerin had a substantial mutagenic potential similar to that of diesel oil.
\end{abstract}

Key words: Tradescantia, stamen-hair assay, toxic emissions, glycerin, diesel

\section{INTRODUCTION}

The global demand for energy has been increasing and a way to meet it is to use alternative fuels. The production of biodiesel from raw vegetable or animal material inevitably results in the coproduction of glycerin (1,2,3-propanetriol), also known as glycerol. Due to its properties, glycerin is commonly used by the food, cosmetic and pharmaceutical industries (Carmines and Gaworski 2005; McNeil et al. 2012). Approximately $100 \mathrm{~kg}$ of glycerin are produced per ton of biodiesel. However, the absorption capacity of the industries is limited, leading to search for new ways of its utilization (McNeil et al. 2012). Many authors have worked with glycerin as a fuel, proving the possibility of employing it for this purpose (Crnkovic et al. 2012). Nevertheless, the use of alternative fuels requires studies to quantify their toxic effects to the environment and humans and compare them with those traditionally used.

The use of biosensor plants, plants that respond to pollutants with no visible effects, presenting molecular, cellular, physiological and biochemical alterations (Temmerman et al. 2004), to evaluate pollution levels has shown additional advantages in comparison with the traditional methods of monitoring. The advantages include low cost of installation, no need of sophisticated instruments for measurement, efficiency in the monitoring of large areas and long periods of time, and viability to evaluate the chemical elements present in low

*Author for correspondence: iavila@feg.unesp.br 
concentrations (Guimarães et al. 2000; Carreras and Pignata 2001). Although the genotoxic effects observed in the plants cannot be extrapolated directly to human populations, the results of experiments with the plants can be taken into consideration for the analysis of atmospheres, due to the high sensitivity of these organisms, even in the situations of low air contamination levels. Therefore, it is possible to affirm that a pollutant that does not cause any detectable damage to the most sensitive species of plants would not affect other organisms, including humans (Guimarães et al. 2000).

The Tradescantia stamen hair (Trad-SH) assay has been one of the most appropriate tests to detect the genetic effects of the chemicals and ionizing radiation and to study the variations in the frequencies of spontaneous somatic mutations (Imai et al. 1991; Ma et al. 1994; Ichikawa and Wushur 2000). The assay is also highly efficient to determine the genotoxicity of liquid and gaseous environmental agents (Ma et al. 1996; Mohammed and Ma 1999). The Trad-SH assay was initially applied to evaluate the genetic effects induced by the nuclear radiation (Nayar and Sparrow 1967; Sparrow et al. 1972) and subsequently adapted to detect the mutagenic agents carried in the air and volatile organic compounds and chemical agents in liquid form (Ma et al. 1994). In humans, a tiny fraction of DNA lesions may or may not induce mutations, but in Tradescantia, the great majority of lesions result in mutations. Thus, an increase in the initial damage frequency (mutations) in Tradescantia may be indicative of mutation occurrence in humans in the same proportion (Ichikawa 1992). Since Tradescantia is highly sensitive to the chemical and physical environmental agents, the plants need only to be exposed to a contaminated environment to produce some effects, with no need of collecting, concentrating or altering the air composition.

The effects of urban pollution have been long studied with the use of biomonitoring and the Trad-SH has been a good alternative to delimit the mutagenic risks in the contaminated environments (Guimarães et al. 2000; Ferreira et al. 2007). Among the air pollutants generated by the combustion of fossil fuels, $\mathrm{SO}_{2}$ is considered one of the most toxic to the plants. It can be absorbed by the roots and stomata. Nitrogen oxides $\left(\mathrm{NO}_{\mathrm{X}}\right)$ are also potentially toxic because they are absorbed by the stomata and inside the leaves, react with water and are dissociated into nitrate and nitrite, acidifying the internal spaces. Hydrocarbons present in the emissions must also be considered components of high mutagenic potential (Freedman 1995). Acrolein is a known environmental pollutant found in many types of biomass emissions (Monteil et al. 1999). According to Beauchamp et al. (1985), several studies on the mutagenic potential of acrolein have shown controversial results, due to its high volatility and instability. Some authors have affirmed that acrolein did not cause chromosome breakage in higher plants (Vicia faba) (Loveless 1951; Izard and Libermann 1978), although Izard (1973) observed interference in the cell division, causing disturbances in the mitotic system.

In previous studies, the Tradescantia biosensor was applied to evaluate the polluted atmospheres, and the concentration of atmospheric gases was provided by environmental agencies (Ferreira et al. 2000; Ferreira et al. 2003; Ferreira et al. 2007) or punctual quantitative measurements of pollutant concentration (Guimarães et al. 2000; Guimarães et al. 2004). This study assessed the mutagenic effects caused by the emissions from the direct combustion of two fuels whose gas concentrations were measured during the exposure of the inflorescences to the toxic emissions. TradSH test using KU-20 clones of Tradescantia was applied to study the ability of the gases from the combustion of diesel and crude glycerin to induce the mutations. The study also dealt with the possibility of replacement of fossil fuel by crude glycerin, an alternative energy source.

\section{MATERIAL AND METHODS}

\section{Materials}

A crude glycerin from bovine tallow, a by-product from Brazilian biodiesel manufacturing, and a Brazilian commercial diesel were used. Table 1 shows the chemical composition of the fuels. The high heating value (HHV) was determined on a bomb calorimeter (IKA C200) according to the ASTM D-2015 standard test method and using samples weighing $1.0 \pm 0.1 \mathrm{~g}$ in three replicate experiments. The ultimate analysis for glycerin was previously determined by Crnkovic et al. (2012) and for diesel oil was provided by the manufacturer.

The biosensor plant, Tradescantia KU-20, was cultivated in a flower bed in the yard of university, 
where there were vehicular and human movement. The control group and the test groups were maintained on the site under the same exposure conditions. The plants were watered three times a week and monthly fertilized with a nutritive solution containing $\mathrm{N}, \mathrm{P}$, and $\mathrm{K}$ in the proportion of 20:20:20 in order to stimulate the growth and inflorescence production.

Table 1 - Ultimate analysis and high calorific value (HHV) of crude glycerin and diesel.

\begin{tabular}{lcc}
\hline Analysis as received & $\begin{array}{c}\text { Crude } \\
\text { glycerin }^{(i)}\end{array}$ & $\begin{array}{c}\text { Diesel } \\
\text { Fuel }^{\text {(ii) }}\end{array}$ \\
\hline Ultimate analysis & & \\
Carbon (\%) & 50.3 & 85.6 \\
Hydrogen (\%) & 9.7 & 14.1 \\
Oxygen (\%) & 37.4 & nd \\
Nitrogen (\%) & 2.6 & 0.3 \\
Sulphur (\%) & nd & nd \\
\hline HHV (MJ/kg) & 25.5 & 45.19 \\
\hline Sources of the ultimate analysis: & ${ }^{(i)}$ Crnkovic et al. $2012 ;{ }^{(i i)}$ \\
Provided by manufacturer (without addition of biodiesel). \\
nd: not detectable
\end{tabular}

\section{Fuels' burning and intoxication systems}

A flamotubular calorimetric furnace composed of twelve combustion chambers in four modules was used for the combustion of the fuels. Each module of furnace was $1 \mathrm{~m}$ long and constituted by a central tube of $305 \mathrm{~mm}$ internal diameter. This tube was superimposed by another tube with an internal diameter of $415 \mathrm{~mm}$, forming a $55 \mathrm{~mm}$ thick chamber of water flow between the two tubes. The module was individually constituted by three calorimetric chambers of $328 \mathrm{~mm}$ length. Each chamber was crossed by two tubes of $25 \mathrm{~mm}$ internal diameter, and two tubes of $19 \mathrm{~mm}$ internal diameter were soldered in its inferior and superior parts. The gaseous emissions from the fuel combustion in the furnace were collected through a metal probe. The concentrations of the gas emissions $\left(\mathrm{O}_{2}, \mathrm{CO}_{2}, \mathrm{CO}\right.$, THC, $\mathrm{NO}_{\mathrm{x}}$ and $\left.\mathrm{SO}_{2}\right)$ were measured in gas analyzers (Horiba Enda 1400 and Tecnomotor), which were connected to the data acquisition system that received and processed the data of the gaseous emissions continuously. After the measurement, the gases were placed in a fumigation chamber containing the inflorescences. The intoxication was performed only after making sure that the system had achieved the equilibrium condition, i.e. after the permanent regime.

For the intoxication tests, the inflorescences (10 to 12 stems) were cut and kept in aeration systems for approximately $2 \mathrm{~h}$ before intoxication. The test groups were placed in a fumigation chamber together with the emissions from the burning of both fuels, i.e., diesel fuel and crude glycerin. They were subjected to intoxication for 30-40 min (according to the duration of the combustion test) and then placed in the aeration systems again, remaining under this condition for approximately four days while the flowers were opening and being analyzed. Figure 1 shows the schematic of the experimental system.

Two process variables were assessed, i.e., excess of air and average temperature of combustion. The excess of air $(\lambda)$ is defined by the equation

$\lambda=\frac{A F_{a c t}}{A F_{T h}}$

where $A F_{\text {act }}$ is the actual air-fuel ratio, and $A F_{T h}$ is the theoretical air-fuel ratio.

The air-fuel ratio (AF) is determined by equation

$$
A F=\frac{m_{\text {air }}}{m_{\text {fuel }}}
$$

where $m_{\text {air }}$ is the mass of air and $\mathrm{m}_{\text {fuel }}$ is the mass of the fuel.

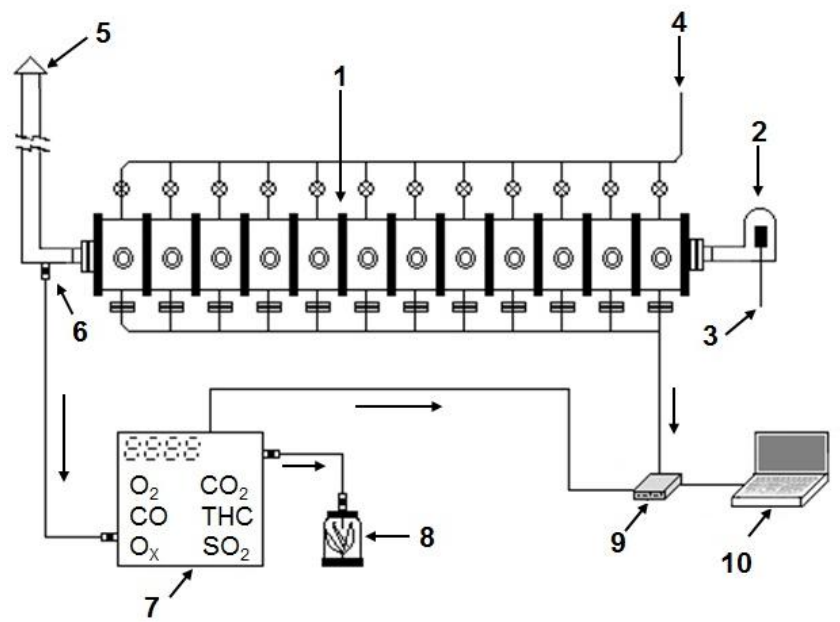

Figure 1-Schematic representation of the experimental system: (1) Flamotubular calorimetric furnace; (2) Burner; (3) Fuel injection; (4) Water flow; (5) Chimney; (6) Emission probe; (7) Gas analyzers; (8) Fumigation chamber; (9) Data acquisition system; (10) Computer.

\section{Analysis of mutagenic events and statistical analysis of data}

For the analysis of the stamen hairs, firstly the anthers and pistils were removed from the fully 
opened flowers and then the six stamens were placed on a slide with drops of water. Using a colony counter and a pair of needles to comb the hairs of each stamen, they were aligned to facilitate the analysis. After the preparation of the slide, they were observed in the microscope under maximum magnification against a white background to reveal the true color of the cells. A sample with more than 30 flowers randomly picked was used to estimate the average of stamen hairs per flower. Three stamens were removed, and the plates were prepared as in the analysis. The number of hairs in each stamen was counted through a microscope. As each flower had six stamens, the results were multiplied by 2 and, the average number of hairs per flower was obtained, considering the total number of samples used. 33 flowers were used, and an average of 368 stamen hairs/flower was obtained. This average number was considered in the analysis of the results because the mutagenic events are expressed in terms of mutations/1000 stamen hairs.

After the number of mutagenic events has been calculated, the results must be expressed in terms of mutant events per 1000 stamen hairs, i.e., the results must be multiplied by 1000 and divided by the average of the number of stamen hairs per flower. The Statistical Analysis was performed using the excel Data Analysis. The significance level was adjusted to $5 \%$. An analysis of variance (ANOVA) was applied to test for significant differences between the analyzed groups. The analysis of multiple comparisons (Tukey test) was used to verify if there were significant differences between the averages of the mutation frequencies in the studied groups.

\section{RESULTS}

The low carbon content and high oxygen content in the crude glycerin led to a lower value of HHV in comparison to diesel oil (Table 1). The HHV of the glycerin was lower than diesel oil, but comparable to ethanol that was around $26 \mathrm{MJ} / \mathrm{kg}$ (Canakci et al. 2013). Therefore, this material could be used in power generation systems. Three pairs of tests were performed, and the experimental conditions adopted and average results of the emissions generated are presented in Table 2. The combustion tests in the furnace were performed in three stages and on the same day, one combustion test with diesel oil and one with glycerin were conducted. The values shown in Table 2 represent average values after the combustion system had achieved the permanent regime.

Table 2 - Experimental conditions adopted in the combustion tests with diesel fuel and crude glycerin, in the furnace, related to the test 1 (D1 and G1), test 2 (D2 and G2) and test 3 (D3 and G3).

\begin{tabular}{lcccccc}
\hline Experimental Data & D1 & D2 & D3 & G1 & G2 & G3 \\
\hline Average Temperature $\left({ }^{\circ} \mathrm{C}\right)$ & 763.4 & 1100.3 & 966.3 & 736.7 & 961.6 & 863.5 \\
Equivalence Ratio $(\lambda)$ & 1.61 & 1.15 & 1.23 & 1.92 & 1.14 & 1.23 \\
Concentration of $\mathrm{O}_{2}(\%)$ & 7.54 & 2.50 & 3.96 & 9.47 & 2.10 & 3.98 \\
Concentration of $\mathrm{CO}_{2}(\%)$ & 8.90 & 11.82 & 10.98 & 7.71 & 13.07 & 11.33 \\
Concentration of $\mathrm{CO}(\mathrm{ppm})$ & 76.00 & 410.00 & 163.00 & 39.00 & 344.00 & 109.00 \\
Concentration of $\mathrm{THC}(\mathrm{ppm})$ & 23.00 & 96.00 & 71.00 & 17.00 & 104.00 & 28.00 \\
Concentration of $\mathrm{NO}_{\mathrm{X}}(\mathrm{ppm})$ & 81.00 & 92.00 & 102.00 & 8.00 & 47.00 & 31.00 \\
Concentration of $\mathrm{SO}_{2}(\mathrm{ppm})$ & 58.00 & 93.00 & 77.00 & 16.00 & 20.00 & 32.00 \\
Acrolein $(\mathrm{ppb}-\mathrm{v} / \mathrm{v})$ & - & - & 0.00 & - & - & 214.0 \\
\hline
\end{tabular}

The tests shown in Table 2 were performed for the assessment of the gas emissions as a function of experimental parameters, such as temperature and excess of air. Therefore, the three pairs of tests were conducted so that the influence of these parameters on the combustion efficiency, which was related to $\mathrm{CO}_{2}, \mathrm{CO}$, and $\mathrm{O}_{2}$ emissions, could be understood. The average temperature when the diesel oil was burned was higher due to their highest HHV (Table 1).
According to Table 2, when the excess of air $(\lambda)$ increased, the temperature decreased. This result was expected because the increase in $\lambda$ caused an increased amount of air mass entering in the process - particularly a higher amount of $\mathrm{N}_{2}$ than $\mathrm{O}_{2}$, reducing the flame temperature and, consequently, the heat exchange and radiation efficiency of the equipment. Regarding the combustion reaction gases $\left(\mathrm{O}_{2}, \mathrm{CO}_{2}, \mathrm{CO}\right)$, in function of the increase in $\lambda$, there was an increase 
in $\mathrm{O}_{2}$ and a decrease in $\mathrm{CO}_{2}$ and $\mathrm{CO}$, characterizing a better combustion. In relation to THC concentrations, there was a decrease with the increase in $\lambda$. The emission of $\mathrm{SO}_{2}$ and $\mathrm{NO}_{\mathrm{X}}$ did not exhibit any default behavior with the variation in $\lambda$.

For each pair of tests (diesel oil and crude glycerin), one control group (samples of Tradescantia non-intoxicated) was assessed, and three control groups were obtained after the three tests. These groups were compared so that they could be united in one representative group. The averages of the mutation frequencies and standard deviations of the control groups are shown in Figure 2. Table 3 presents the Analysis of Variance (ANOVA) of the control groups.

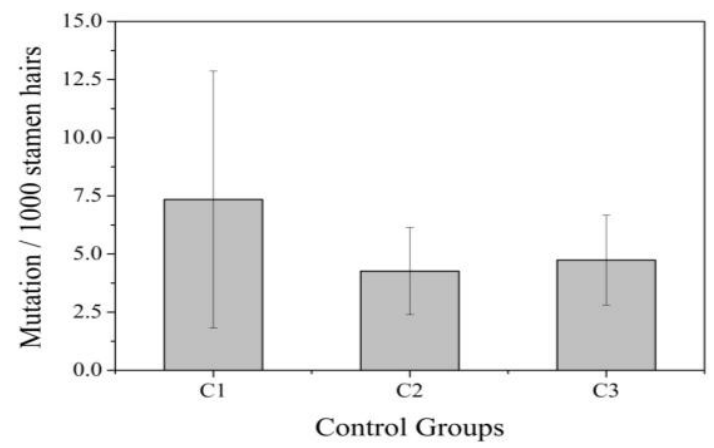

Figure 2 - Average values and respective standard deviations of mutation frequency in stamen hairs of KU-20 clone found in the control groups.

Table 3 - Analysis of variance (ANOVA) of the control groups (Critical value of $F$ in the significance level of $5 \%)$.

\begin{tabular}{lcccccc}
\hline $\begin{array}{l}\text { Variation Sum of } \\
\text { source }\end{array}$ & \multicolumn{2}{c}{$\begin{array}{c}\text { Deguaree } \\
\text { squares of liberty squares }\end{array}$} & $\begin{array}{c}\text { Mean } \\
\mathrm{F}_{\mathrm{STAT}}\end{array}$ & $\begin{array}{c}\boldsymbol{p} \text { - } \\
\text { value }\end{array}$ & $\mathbf{F}_{\mathrm{TABLE}}$ \\
\hline $\begin{array}{l}\text { Between } \\
\text { groups }\end{array}$ & 55.03 & 2 & 27.52 & 2.19 & 0.13 & 3.35 \\
$\begin{array}{l}\text { Inside } \\
\text { groups }\end{array}$ & 339.73 & 27 & 12.58 & & & \\
Total & 394.76 & 29 & & & & \\
\hline
\end{tabular}

Based on the ANOVA results, it was possible to either accept or reject the null hypothesis of the group similarity from the calculation of $F$. Table 3 showed that $\mathrm{F}_{\mathrm{STAT}}$ was inferior to $\mathrm{F}_{\mathrm{TABLE}}$ and $p$ value was under the significance level. No significant statistical differences were found in the comparison of the three control groups. A control medium $\left(\mathrm{C}_{\mathrm{M}}\right)$ was obtained from the average of the three individual controls of each pair of tests in order to compare the mutagenic responses of the samples with the natural variation observed in the environment. From the three tests, a total of seven groups was obtained - six intoxicated groups, resulting from the intoxication with emissions of diesel oil (D1, D2, and D3 groups) and crude glycerin (G1, G2 and G3 groups) and a control group $\left(\mathrm{C}_{\mathrm{M}}\right)$.

The results of the mutagenic responses of the groups subjected to gaseous emissions from the combustion of diesel fuel and crude glycerin are shown in Figure 3. The average number, standard deviation, and the rates of mutations of all groups were measured by the number of pink cells and expressed in terms of mutations/1000 stamen hairs. The intoxication time was around $30 \mathrm{~min}$ for tests 1 and 2, and around $40 \mathrm{~min}$ for test 3 .

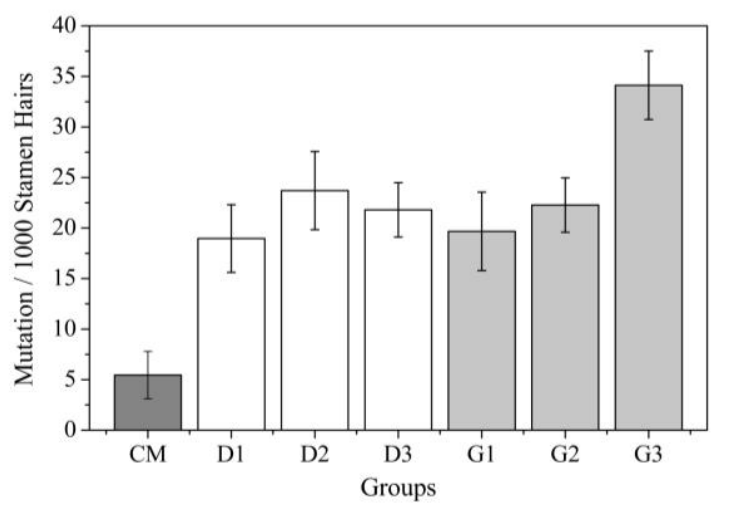

Figure 3 - Average values and respective standard deviations of mutation frequency in stamen hairs of KU-20 clone found in all the groups.

As expected, the values of the mutation frequencies obtained for the control groups (Fig. 3) were significantly lower than those observed for intoxicated groups. Among the intoxicated groups, the average values of mutagenic events were approximately constant $(21 \pm 3$ of Mutation/1000 stamen hairs), except for the G3 group ( $34 \pm 3$ Mutation/1000 stamen hairs). As the test 1 was performed with higher value of $\lambda$, the lowest mutation frequencies for this test were expected due to the emissions dilution. The tests 2 and 3 were executed with values approximate of $\lambda$, but in the test 3 , the inflorescences had a longer time of exposure to the gaseous emissions. Thus, higher mutagenesis was expected in the last test. 
However, the mutations produced by the diesel oil combustion remained approximately constant in the three tests.

The ANOVA was applied to compare the groups intoxicated (Fig. 3) statistically. As shown in Table $4, \mathrm{~F}_{\text {STAT }}$ was superior to $\mathrm{F}_{\mathrm{TABLE}}$ and $p$-value was higher than the significance level. Therefore, according to ANOVA, the null hypothesis of similarity was rejected.

The Tukey test was applied to determine which samples differed from each other statistically. Table 5 shows the data of the Tukey analysis.

Table 4 - Analysis of variance (ANOVA) of the intoxicated and control groups (Critical value of $\mathrm{F}$ in the significance level of 5\%).

\begin{tabular}{lcccccc}
\hline Variation source & Sum of squares & degree of liberty & Mean squares & $\mathbf{F}_{\text {STAT }}$ & $\boldsymbol{p}$-value & $\mathbf{F}_{\text {TABLE }}$ \\
\hline Between groups & 4293.48 & 6 & 715.58 & 66.2 & $2.56 \times 10^{-25}$ & 2.25 \\
Inside groups & 680.95 & 3 & 10.81 & & & \\
\hline
\end{tabular}

Table 5 - Application of Tukey test (value of $\mathrm{q}_{T A B L E}=4.310, \mathrm{SE}=1.040$ ).

\begin{tabular}{|c|c|c|c|c|}
\hline Group $1 \times$ Group 2 & $\begin{array}{c}\bar{y}_{1}-\bar{y}_{2} \\
\text { Mutation/1000 stamen hair }\end{array}$ & $q_{\text {STAT }}$ & $q_{S T A T}-q_{T A B L E}$ & Analysis \\
\hline $\mathrm{G} 3 \times \mathrm{D} 2$ & 10.427 & 9.376 & 5.72 & Averages differ \\
\hline $\mathrm{G} 3 \times \mathrm{G} 2$ & 11.848 & 10.654 & 7.09 & Averages differ \\
\hline $\mathrm{G} 3 \times \mathrm{D} 3$ & 12.322 & 11.08 & 7.54 & Averages differ \\
\hline $\mathrm{G} 3 \times \mathrm{G} 1$ & 14.455 & 12.998 & 9.59 & Averages differ \\
\hline $\mathrm{G} 3 \times \mathrm{D} 1$ & 15.166 & 13.637 & 10.28 & Averages differ \\
\hline $\mathrm{G} 3 \times \mathrm{C}_{\mathrm{M}}$ & 28.673 & 25.783 & 23.27 & Averages differ \\
\hline $\mathrm{D} 2 \times \mathrm{G} 2$ & 1.422 & 1.279 & -2.94 & - \\
\hline $\mathrm{D} 2 \times \mathrm{D} 3$ & 1.896 & 1.705 & -2.49 & - \\
\hline $\mathrm{D} 2 \times \mathrm{G} 1$ & 4.028 & 3.622 & -0.44 & - \\
\hline $\mathrm{D} 2 \times \mathrm{D} 1$ & 4.739 & 4.262 & 0.25 & Averages differ \\
\hline $\mathrm{D} 2 \times \mathrm{C}_{\mathrm{M}}$ & 18.246 & 16.407 & 13.24 & Averages differ \\
\hline $\mathrm{G} 2 \times \mathrm{D} 3$ & 0.474 & 0.426 & -3.85 & - \\
\hline $\mathrm{G} 2 \times \mathrm{G} 1$ & 2.607 & 2.344 & -1.80 & - \\
\hline $\mathrm{G} 2 \times \mathrm{D} 1$ & 3.318 & 2.983 & -1.12 & - \\
\hline $\mathrm{G} 2 \times \mathrm{C}_{\mathrm{M}}$ & 16.825 & 15.129 & 11.87 & Averages differ \\
\hline $\mathrm{D} 3 \times \mathrm{G} 1$ & 2.133 & 1.918 & -2.26 & - \\
\hline $\mathrm{D} 3 \times \mathrm{D} 1$ & 2.844 & 2.557 & -1.58 & - \\
\hline $\mathrm{D} 3 \times \mathrm{C}_{\mathrm{M}}$ & 16.351 & 14.703 & 11.42 & Averages differ \\
\hline $\mathrm{G} 1 \times \mathrm{D} 1$ & 0.711 & 0.639 & -3.63 & - \\
\hline $\mathrm{G} 1 \times \mathrm{C}_{\mathrm{M}}$ & 14.218 & 12.785 & 9.37 & Averages differ \\
\hline $\mathrm{D} 1 \times \mathrm{C}_{\mathrm{M}}$ & 13.507 & 12.146 & 8.68 & Averages differ \\
\hline
\end{tabular}

$\mathrm{q}_{\text {STAT }}>\mathrm{q}_{\text {TABLE }} \rightarrow(+)$ Averages differ; $\mathrm{q}_{\text {STAT }}<\mathrm{q}_{\text {TABLE }} \rightarrow(-)$ Averages do not differ.

\section{DISCUSSION}

In the Tradescantia stamen hair mutation assay (Trad-SH), the main cells are the mitotic cells of the stamen hair under development in young inflorescences. The assay is based on the coloration heterozygosis of cells (dominant character $=$ "blue" and recessive character $=$ "pink"). Once all the cells have an allele to the blue color and another to the pink color, a simple mutation causes a phenotypic alteration of easy perception (Nayar and Sparrow 1967; Ma et al. 1994; Rodrigues et al. 1997). The cells of a stamen hair originate from a single epidermal cell of the filament. All the cells in each hair are generated by mitosis from the apical or sub-apical cells. Therefore, a pink mutant cell may repeatedly divide and give rise to a string of pink cells. Thus, this string is considered a single mutation event, once it originates from a single mutation. Two or more pink mutant cells separated by blue normal cells are considered distinct mutagenic events.

The Tukey test (Table 5) showed that among the intoxicated groups, only the average of pink mutations of G3 group differed from the average of the other groups. As expected, all the samples 
intoxicated with gaseous emissions generated by diesel fuel and crude glycerin burning showed a higher average frequency of mutagenic events than the control group. In the evaluation of the diesel oil emissions, D2 group showed a mutation rate statistically higher than that of D1 group, but both rates were similar to that of D3 group. According to Table 2, D2 group was subjected to gaseous concentrations higher than that observed in the D1 group, but very close to that of D3 group, except the concentration of $\mathrm{CO}$, which was higher than that of all other groups. Since the D1 and D2 groups were similar to D3 group, it was assumed that the difference between them occurred due to a natural variation in both gases composition and plants physiology.

In the analysis of the groups intoxicated from glycerin combustion, G3 group was subjected to the highest concentrations of $\mathrm{SO}_{2}$ (Table 2) and longer exposure time (around $40 \mathrm{~min}$ ). G2 group was subjected to the highest concentrations of $\mathrm{CO}$, THC and $\mathrm{NO}_{\mathrm{X}}$, but showed an average of mutagenic events similar to that of G1 group and lower than the one of G3 group. Comparing G1 and G2 groups with the others, the ones intoxicated with diesel oil emissions were subjected to higher concentrations of $\mathrm{SO}_{2}$, and $\mathrm{D} 2$ group, subjected to a higher concentration of $\mathrm{CO}$, showed rates of pink mutations higher than that of D1 group. D3 group was subjected to experimental conditions (temperature and $\lambda$ ) and exposure time to toxic emissions close to the conditions adopted for G3 group (Table 2). However, the mutagenic events of D3 group were quite lower than those of G3 group and similar to those of the other groups.

The two first pair of tests (D1, G1, D2 and G2 groups) did not show differences between the groups intoxicated with the emissions from the combustion of both fuels. Thus, the presence of acrolein, commonly released in the glycerin combustion (Monteil et al. 1999), was assessed in the last pair of test (D3 and G3 groups). As expected, it was not found in the diesel oil emissions and its concentration in the glycerin emissions (Table 2) was lower than the concentrations found in other studies (Izard and Libermann 1978; Beauchamp et al. 1985). These studies also reported that at the experimental concentrations, there was no interfere in chromosomal DNA. In the present study, as the pollutants analyzed were not present in higher concentrations in the G3 group and behaved differently from the others with a higher rate of mutagenic events, the results of the acrolein toxicity were not conclusive. The presence of acrolein in the G3 group and its absence in the D3 group, however, might be an indication that it was among the substances that caused an increase in the mutant frequency in the G3 group.

According to the literature, the gaseous emissions such as $\mathrm{NO}_{\mathrm{X}}, \mathrm{SO}_{2}, \mathrm{CO}$ and $\mathrm{THC}$ were considered toxic and mutation inductors (Clark and Vigil 1980; Arey et al. 1992; Freedman 1995; Grant and Briggs 2002). The increase in the time of exposure to toxic emissions was also assessed and showed evidences that it caused an increase in the number of pink mutations. This study did not conclude, which variables caused more damage to G3 group. However, it could be stated that glycerin was a product with impurities and more heterogeneous composition in comparison to diesel. Since the combustion system simulates a real furnace with burning process too unstable, measurements are influenced by the variations within it during firing. This study took into consideration the difficulty and lack of details about the combustion process of crude glycerin, whose composition was not fully known.

\section{CONCLUSIONS}

The high heating value (HHV) was determined, which showed that crude glycerin had the potential for use in power generation systems. The present study assessed the efficiency of applying of TradSH assay by exposing seedlings in the chambers of flux of gaseous agents to determine a possible mutagenic potential of gases emitted by different fuels. Diesel oil and glycerin showed considerable mutagenic effects, since both showed a higher increase in the DNA injury of plants than that observed in the control group. Only one group of glycerin (G3) showed a higher rate of mutagenic events than the other groups after the application of analysis of variance (ANOVA) and Tukey Test. The analysis of the experimental data of all the groups did not allow determining a variable that could explain the increase in the pink mutations frequency observed in the G3 group. Thus, it could be assumed that the process of glycerin combustion was difficult to describe and complex, since the fuel had an unclear composition and some unidentified factor occurred exceptionally in this test (G3) with no recurrent character. 
Glycerin is a waste material generated in the biodiesel production and its use as an alternative fuel is an important aspect to be considered. However, present findings have shown that this material, similarly to diesel, could exert considerable mutagenic effects.

\section{ACKNOWLEDGEMENTS}

The authors are grateful to $\mathrm{CNPq}$ - National Council for Scientific and Technological Development for the financial support provided to this research (Process 159754/2011-9). The assistance from Prof. Angela C. P. Giampedro is also acknowledged.

\section{REFERENCES}

Arey J, Harger WP, Helmig D, Atkinson R. Bioassaydirected fractionation of mutagenic $\mathrm{PAH}$ atmospheric photooxidation products and ambient particulate extracts. Mutat Res Lett. 1992; 281(1): 67-76.

Beauchamp RO, Andjelkowitch DA, Kligerman AD, Morgan KT, Helch H.A. A critical review of the literature on acrolein toxicity. Crit Rev Toxicol. 1985; 14(4): 309-380.

Carmines EL, Gaworski CL. Toxicological evaluation of glycerin as a cigarette ingredient. Food Chem Toxicol. 2005; 43 (10) 1521-1539.

Canakci, M, Ozsezen, AN, Alptekin E, Eyidogan, M. Impact of alcohol-gasoline fuel blends on the exhaust emission of an SI engine. Renewable Energy. 2013; 52(1): 111-117.

Carreras HA, Pignata ML. Comparison among air pollutants, meteorological conditions and some chemical parameters in the transplanted lichen Usnea amblyoclada. Environ Pollut. 2001; 111(1): 45-52.

Clark CR, Vigil CL. Influence of rat lung and liver homogenates on the mutagenicity of diesel exhaust particulate extracts. Toxicol Appl Pharmacol. 1980; 56(1): 110-115.

Crnkovic PM, Koch C, Ávila I, Mortari DA, Cordoba AM, Santos AM. Determination of the activation energies of beef tallow and crude glycerin combustion using thermogravimetry. Biomass Bioenergy. 2012; 44: 8-16.

Ferreira MI, Domingos M, Gomes HA, Saldiva PHN, Assunção JV. Evaluation of mutagenic potential of contaminated atmosphere at Ibirapuera Park, São Paulo - SP, Brazil, using the Tradescantia stamenhair assay. Environ Pollut.2007; 145( 1): 219-224.
Ferreira MI, Petrenko H, Lobo DJA, Rodrigues GS, Moreira A, Saldiva PHN. In Situ monitoring of the mutagenic effects of the gaseous emissions of a solid waste incinerator in metropolitan São Paulo, Brazil, using the Tradescantia Stamen-Hair Assay. Air Waste Manage Assoc. 2000; 50: 1852-1856.

Ferreira MI, Rodrigues GS, Domingos M, Saldiva PHN. In Situ monitoring of mutagenicity of air pollutants in São Paulo City using Tradescantia-SHM Bioassay. Braz Arch Biol Technol. 2003; 46(2): 253258.

Freedman B. Environmental ecology. The ecological effects of pollution, disturbance and other stresses. San Diego: Academic Press Inc., $2^{\text {nd }}$. ed., 1995.

Grant A, Briggs, AD. Toxicity of sediments from around a North Sea oil platform: are metals or hydrocarbons responsible for ecological impacts? Mar Environ Res. 2002; 53(1): 95-116.

Guimarães ET, Domingos M, Alves ES, Caldini Jr. N, Lobo DJA, Lichtenfels AJFC, Saldiva PHN. Detection of the genotoxicity of air pollutants in and around the city of São Paulo (Brazil) with the Tradescantia-micronucleus (Trad-MCN) assay. Environ Exp Bot. 2000; 44(1): 1-8.

Guimarães ET, Macchione M, Lobo DJA, Domingos M, Saldiva PHN. Evaluation of the mutagenic potential of urban air pollution in São Paulo, Southeastern Brazil, using the Tradescantia stamenhair assay. Environ Toxicol. 2004; 19(6): 578-584.

Ichikawa S, Wushur, S. Analyses of spontaneous pink mutant events in the stamen hairs of Tradescantia clone BNL 4430 cultivated in a nutrient solution circulating growth chamber. Mutat Res, Genet Toxicol Environ Mutagen. 2000; 472(1-2): 37-49.

Ichikawa S. Tradescantia stamen-hair system as an excellent botanical tester of mutagenicity: its responses to ionizing radiations and chemical mutagens, and some synergistic effects found. Mutat Res Fundam Mol Mech Mutagen. 1992; 270(1): 3-22.

Imai T, Ichikawa S, Sanda-Kamigawara M. Variation of spontaneous somatic mutation frequency on the stamen hairs of a mutable clone of Tradescantia, KU 20. Jpn J Genet. 1991; 66(4): 501-511.

Izard C, Libermann C. Acrolein. Mutat Res. 1978; 47(2): 115-138.

Izard C. Effect of acrolein on the cellular division, the cycle, and the synthesis of DNA in Vicia faba. Comptes Rendus de l'Académie des Sciences - Series D 276(II). 1973; 1745-1747.

Loveless A. Qualitative aspects of the chemistry and biology of radiomimetic (mutagenic) substances. Nature (London). 1951; 167: 338-342. 
Ma TH, Cabrera GL, Cebulska-Wasilewska A, Chen R, Loarca F, Vandenberg AL, Salamone MF. Tradescantia stamen hair mutation bioassay. Mutat Res, Fundam Mol Mech Mutagen.1994; 310(2): 211220.

Ma TH, Xu C, Liao S, McConnell H, Jeong BS, Won CD. In situ monitoring with the Tradescantia bioassays on the genotoxicity of gaseous emissions from a closed landfill site and an incinerator. Mutat Res Environ Mutagen Relat Subj. 1996; 359(1): 3952.

McNeil J, Day P, Sirovski F. Glycerine from biodiesel: The perfect diesel fuel. Process Saf Environ Prot. 2012; 90(3): 180-188.

Mohammed KB, Ma TH. Tradescantia-micronucleus and -stamen hair mutation assays on genotoxicity of the gaseous and liquid forms of pesticides. Mutat Res Fundam Mol Mech Mutagen. 1999; 426(2): 193-199.

Monteil C, Le Prieur E, Buisson S, Morin JP, Guerbet M, Jouany JM. Acrolein toxicity: comparative in vitro study with lung slices and pneumocytes type II cell line from rats. Toxicol. 1999; 133: 2-3.
Nayar GG, Sparrow A. Radiation-induced somatic mutations and the loss of reproductive integrity in Tradescantia stamen hairs. Radiat Bot. 1967; 7(4): 257-260.

Rodrigues GS, Ma TH, Pimentel D, Weinstein LH, Ichikawa S. Tradescantia Bioassays as Monitoring Systems for Environmental Mutagenesis: A Review. Crit Rev Plant Sci.1997; 16(4): 325-359.

Sparrow AH, Underbrink AG, Rossi HH. Mutations induced in Tradescantia by small doses of x-rays and neutrons: Analysis of dose-response curves. Sci. 1972; 176: 916-918.

Temmerman L, Bell JNB, Garrec JP, Klumpp A, Krause GHM, Tonneijck AEG. Biomonitoring of air pollutants with plants - considerations for the future, in: Klumpp, A, Ansel, W, Klumpp G. (Eds.), Urban air pollution, bioindication and environmental awareness, Cuvillier Verlag, Göttingen. 2004: $337-$ 373.

Received: May 19, 2014; Accepted: October 01, 2014 